\title{
WebQuests: Tecnologias, multiletramentos e a formação do professor de inglês para a era do ciberespaço
}

\section{WebQuests: tecnologies, multiliteracies and the English teacher's professional development for the cyberspace}

\author{
Reinildes Dias* \\ Universidade Federal de Minas Gerais \\ Belo Horizonte - Minas Gerais / Brasil
}

\begin{abstract}
RESUMO: O objetivo principal deste artigo é discutir o papel das tecnologias digitais nas mudanças sociais, econômicas e comunicacionais da era contemporânea. Tais mudanças influenciam diretamente a formação do professor de inglês. Imperativo se torna, então, o desenvolvimento de seus multiletramentos para que se possa construir e produzir significados de textos digitais multimodais de forma crítica. A investigação empírica do estudo revela que as WebQuests constituem ambientes adequados a esse fim, isto é, ao desenvolvimento profissional do professor em relação aos multiletramentos. Parece possível afirmar que um professor multiletrado pode provocar mudanças em seu fazer pedagógico e um realinhamento às necessidades de seus alunos para os desafios da era do ciberespaço.
\end{abstract}

PALAVRAS-CHAVE: WebQuests, multiletramentos, multimodalidade, aprendizagem colaborativa, formação do professor de inglês.

\begin{abstract}
The main purpose of this article is to discuss the role of digital technologies on social, economic and communication changes in contemporary times. This in turn directly influences the English teacher's professional development. It is essential that this educator gets involved with multimodal digital texts to construct and produce meanings in a critical way. Findings from the present study provide evidence that WebQuests can be adequate environments for this end, that is, the English teacher's professional development towards multiliteracies. It seems possible to say that a multiliterate teacher may foster changes in his/her pedagogical practice and a realignment to the needs of his/her students for the challenges of the cyberspace era.

KEYWORDS: WebQuests, multiliteracies, multimodality, collaborative learning, English teacher's professional development.
\end{abstract}

\footnotetext{
* reinildes@gmail.com
} 
As tecnologias digitais, especialmente as ferramentas da web 2.0, empoderam o cidadão do século XXI para assumir uma voz globalmente conectada e ainda facilitam a comunicação e a colaboração entre pessoas do mundo inteiro por meio de múltiplas linguagens - a verbal, a imagética, a gestual, a sonora e a espacial, por exemplo. A sociedade mudou sob a influência dessas tecnologias e, com isso, novos tipos de letramento são necessários, inclusive à comunidade discursiva dos professores de inglês. Não basta ao indivíduo saber comunicar apenas pela leitura e escrita - tem ainda de ser capaz de lidar com outros modos de comunicação, além de desenvolver consciência crítica em relação ao que ouve, lê, escreve e vê. Precisa também mostrar habilidades no meio digital, principalmente na internet, para construir e produzir conhecimento. Socializar com pessoas próximas e distantes geográfica e culturalmente tornou-se uma prática do cotidiano, possível a todos através do meio virtual. Interagir virtualmente com outros colegas de profissão tornase um dos meios favoráveis à formação reflexiva do professor de inglês.

O espaço do trabalho vem também incorporando mudanças: de uma estrutura altamente hierarquizada, enrijecida e com o poder centralizado na figura do chefe, transmuda para uma organização na qual as tomadas de decisão e o agir para resolver problemas são colaborativos e dependentes de um trabalho em equipe. A sala de aula incorpora tais características e o professor de inglês passa a assumir o papel de orquestrador das ações de aprendizagem, usualmente colaborativas (HYLAND, 2004; 2007; VYGOTSKY, 1996). As capacidades interpessoais e intrapessoais do indivíduo tornam-se altamente valorizadas no trabalho de criar, comunicar e colaborar em situaçôes presenciais, face a face, e no meio on-line. De práticas de letramento para ler e escrever (SOARES, 2003), necessárias na era da tecnologia do meio impresso, em que o texto escrito era a fonte dominante de conhecimento e de poder, avançamos em direção aos multiletramentos, influenciados pelas mudanças econômicas, tecnológicas e sociais da era digital, incluindo a ubiquidade de textos multimodais que combinam mais de um modo semiótico em sua tessiturao linguístico, o imagético, o espacial, o gestual, o sonoro (ANSTEY; BULL, 2010; COPE; KALANTZIS, 2000; KALANTZIS; COPE, 2008; KRESS, 2003). A pessoa multiletrada da era digital precisa combinar múltiplas habilidades, conhecimento multicultural, comportamentos adequados aos diferentes contextos para exercer seus direitos e deveres de cidadão no presente e no futuro. Tornam-se necessárias, então, mudanças no agir pedagógico do professor de inglês que só poderão ser alcançadas por meio de um processo de 
formação que vise ao desenvolvimento das práticas multiletradas da contemporaneidade.

Neste cenário, o letramento digital, como um dos componentes essenciais do seu multiletramento, torna-se capacidade básica para a formação e a atuação do professor de inglês em seu contexto educacional, uma vez que a tela do computador passa a ser a estrutura textual dominante na nova era (KRESS, 2003). Ademais, pode-se afirmar que usualmente as práticas sociais pelo uso da linguagem por seus alunos são permeadas pelas novas tecnologias, uma vez que são capazes de navegar com facilidade pelo meio digital através de recursos virtuais, tais como o Facebook, o Twitter, o iPod, o smartphone, entre vários outros. Grande parte dos professores de inglês brasileiros, entretanto, não desenvolveu expertise para a integração das novas tecnologias e os multiletramentos durante a sua graduação, não tendo aprendido, por exemplo, a lidar com as mais simples ferramentas da web e a interpretar o mundo sob múltiplas perspectivas. É preciso, então, que passe a problematizar e a refletir sobre o grande impacto social das tecnologias da web nas diferentes esferas da sociedade, de modo a assumir açôes educativas cujos efeitos sejam sentidos também no ambiente escolar. Além disso, pelo seu letramento digital, o professor de inglês passa a perceber que novas formas de textos multimodais como, por exemplo, blogs, wikis, podcasts, WebQuests, vídeos, fazem parte do cotidiano das notícias, anúncios e instruçôes com os quais interage e que pode utilizá-los como ferramentas de autoformação e aprendizagem para seus alunos. Pelo seu letramento digital e consequente incorporação de recursos da web à sua prática pedagógica, o fazer educativo do professor de inglês pode passar a oferecer

múltiplos caminhos e alternativas, distanciando-se do discurso monológico da resposta certa, da sequência linear de conteúdos, de estruturas rígidas dos saberes prontos, com compromissos renovados em relação à flexibilidade, e à variedade, além da contextualização no mundo das relaçōes sociais e de interesses dos envolvidos no processo de aprendizagem. (GUIMARÃES; DIAS, 2002, p. 23).

Neste artigo ${ }^{1}$ pretendo, primeiro, discutir o termo multiletramentos (ANSTEY; BULL, 2010; COPE; KALANTZIS, 2000) e relacioná-lo ao conceito de letramento para ler e escrever (SOARES, 2003), a fim de evidenciar a necessidade de compromissos renovados com uma educação transformadora (FREIRE, 1987)

\footnotetext{
${ }^{1}$ A pesquisa relatada neste artigo foi desenvolvida durante os meus estudos de pósdoutorado na PUC-SP.
} 
no processo de formação do professor de inglês. Realço a noção de WebQuests como ambientes multimodais de aprendizagem, apropriados para o desenvolvimento dos multiletramentos, e também os princípios da aprendizagem colaborativa para apoiar o processo de formação do professor na contemporaneidade. Relato também as ações de uma investigação empírica relacionada à pergunta de pesquisa: "As WebQuests favorecem o desenvolvimento do letramento digital do professor de inglês de modo a se formar para os desafios educacionais da era virtual?" O estudo evidencia que esses ambientes podem favorecer a formação do professor para as mudanças advindas da complexidade das inter-relaçôes da era virtual. Sugiro, ao final, que as WebQuests sejam utilizadas como ferramentas sociais para formar o professor de inglês, visando ao seu empoderamento diante dos multiletramentos da era atual, especialmente as interrelações entre o digital, o multimodal e o crítico. ${ }^{2}$

\section{Multiletramentos}

\section{Letramento para ler e escrever significa}

o estado ou condição de quem interage com diferentes portadores de leitura e de escrita, com diferentes gêneros e tipos de leitura e de escrita, com as diferentes funções que a leitura e a escrita desempenham na nossa vida. Enfim, [...] é o estado ou condição de quem se envolve nas numerosas e variadas práticas sociais de leitura e de escrita. (SOARES, 2003, p. 44).

O termo multiletramentos, cunhado pelo New London Group (1996), ${ }^{3}$ destaca dois aspectos estreitamente imbricados da sociedade contemporânea: (1) a proliferação de meios semióticos diferentes em textos de gêneros

${ }^{2}$ Letramento digital: relacionado ao uso e integração dos recursos da web às atividades pessoais, acadêmicas e profissionais do cotidiano.

Letramento multimodal: capacidade do indivíduo para lidar com os textos multimodais, tanto os impressos quanto os digitais, da era contemporânea.

Letramento crítico: especificamente relacionado a questôes de linguagem e poder e ao desenvolvimento da consciência crítica de alunos e professores em formação para o enfrentamento dos desafios da era cibernética.

${ }^{3}$ Grupo de pesquisadores internacionais reunidos em New Hampshire (USA). Documento resultante de encontro em 2006 disponível em <http://wwwstatic.kern.org/filer/ blogWrite44ManilaWebsite/paul/articles/A_Pedagogy_of_Multiliteracies_Designing Social_Futures.htm >. 
diversificados, em que o modo linguístico ou verbal configura-se apenas como um deles, ao lado do visual ou imagético, do espacial, do gestual e do sonoro; e (2) a crescente diversidade linguística e cultural caracterizada pelas interrelações locais e globais entre diferentes culturas e etnias, facilitadas pelas tecnologias digitais. Assim, a formação para os multiletramentos envolve o desenvolvimento da capacidade do professor para lidar com a multimodalidade (KRESS, 2003), cada vez mais presente nos textos da era atual, tanto nos impressos quanto nos digitais, e para agir criticamente em diferentes contextos sociais por meio das tecnologias digitais frente à diversidade cultural, linguística e étnica das interações on-line.

As práticas multiletradas têm, pois, sua origem e influência nas mudanças sociais, culturais e tecnológicas advindas da era do ciberespaço. Com isso, o cidadão contemporâneo precisa tornar-se aberto à diversidade cultural, respeitar a pluralidade étnica e saber conviver on-line. Acima de tudo, precisa interpretar textos multimodais e perceber suas lacunas, silêncios e tendenciosidade, ou seja, desenvolver o seu letramento crítico. Cabe salientar que todo e qualquer texto é produzido sob o ponto de vista de quem o cria e dos interesses sociais, econômicos e culturais que representa. Textos não são neutros e são sempre fontes de poder. Se, por um lado, as mensagens não são neutras do ponto de vista de quem as produz, por outro lado, a compreensão delas é influenciada por quem as ouve ou lê e acaba sendo impregnada dos valores, pontos de vista sociais e culturais e crenças durante o processo de construção do seu significado (WALLACE, 2005). Isso significa que o letramento crítico subjaz o processo de compreensão e produção de textos.

O letramento digital refere-se, pois, em linhas gerais, à capacidade do indivíduo para compreender e produzir textos orais e escritos no meio digital e para aplicar o conhecimento construído a outros contextos socioculturais. Indivíduos já letrados digitalmente sabem colaborar on-line e usar regras de negociação, visando a soluçōes consensuais. Lidam com as tecnologias digitais de maneira eficiente e incorporam diferentes tipos de gadgets $^{4}$ ao seu modo de pensar e de agir socialmente. São parte da cultura cibernética do acesso rápido a qualquer tipo de informação e às interaçôes locais e globais com amigos, familiares e desconhecidos no mundo inteiro, participantes de blogs, Twitters, Orkuts e de outros espaços sociais virtuais próprios para interaçôes

\footnotetext{
${ }^{4}$ Gadgets: equipamentos pequenos capazes de possibilitar interações virtuais entre pessoas localizadas em várias partes do mundo. iPods e iPhones, por exemplo.
} 
on-line. Estreitamente relacionado ao letramento digital, o letramento multimodal (WALSH, 2010) refere-se à capacidade do indivíduo para ler, assistir e produzir textos orais e escritos, impressos ou digitais, que combinam vários modos semióticos - o linguístico, o imagético, o sonoro, o gestual, o espacial. Embora a maioria dos textos impressos, como, por exemplo, capas de revistas, histórias em quadrinhos, manuais de instruçōes, combinem mais de um código semiótico em sua tessitura, a multimodalidade ganha maior expressividade nos gêneros digitais da tela do computador (DIAS, 2011).

O letramento crítico, por sua vez, subjaz a todas as açôes pela linguagem e envolve a análise e o posicionamento crítico de quem lê, ouve e produz textos orais e escritos, considerando, especialmente, a intertextualidade entre textos, as relaçóes entre linguagem e poder e as práticas sociais pela linguagem que são estabelecidas por meio de gêneros. Refere-se também ao empoderamento do indivíduo para questionar as atitudes, valores e crenças nas entrelinhas dos textos. Cabe ao indivíduo crítico estabelecer os propósitos dos textos e das intençōes autorais, entender que textos não são neutros, levar em conta o poder da linguagem na sociedade contemporânea, reconhecer que textos podem ter múltiplas interpretações e que o processo de ler e de escrever é dinâmico, demandando a participação ativa dos envolvidos. ${ }^{5}$ A posiçăo social do autor e o lugar de onde fala são também analisados e questionados pelos indivíduos criticamente letrados.

Pode-se afirmar, então, que o indivíduo multiletrado, capaz de lidar com os multiletramentos exigidos pelas mudanças sociais da era contemporânea,

interpreta, usa e produz textos escritos, eletrônicos e ao vivo que empregam meios semióticos diferentes, tendo em vista propósitos econômicos, sociais, políticos e cívicos diferenciados em contextos sócio e culturalmente diversos. (ANSTEY; BULL, 2006, p. 41). ${ }^{6}$

\section{WebQuests}

WebQuests são ambientes multimodais de aprendizagem colaborativa que incentivam os participantes a interagir no processo de desenvolvimento

\footnotetext{
${ }^{5}$ http://www.education.tas.gov.au/curriculum/standards/english/english/teachers/ critlit

${ }^{6}$ Minha tradução para "interpret, use, and produce electronic, live, and paper texts that employ linguistic, visual, auditory, gestural, and spatial semiotic systems for social, cultural, political, civic, and economic purposes in socially and culturally diverse contexts".
} 
de projetos on-line pelo uso da web e de seus recursos. Representam um modelo de pesquisa orientada, focada na busca de informaçôes para resolver uma situação problema, realizada no espaço da internet (DODGE; $\mathrm{MARCH}$, 2007; DODGE, 2008). ${ }^{7}$ As fontes de pesquisa são recomendadas por meio dos links fornecidos para que os participantes não se "afundem" no oceano de informaçôes da internet - são, pois, uma estrutura de aprendizagem assistida (MARCH, 2004). ${ }^{8}$

Idealizados pelos dois pesquisadores Bernie Dodge e Tom March, da Universidade de San Diego, nos Estados Unidos, esses ambientes ganharam a aceitação de professores e educadores em várias partes do mundo, inclusive no Brasil. As WebQuests centram-se no uso das tecnologias da web para fornecer suporte à colaboração, favorecer as interaçōes e facilitar a troca e a distribuição de competências entre os envolvidos. São, pois, ambientes de aprendizagem compartilhada que envolvem os participantes no processo de negociação de ideias, conceitos e soluçôes consensuais. Como exemplares do aprender em colaboração, apoiam a compreensão e a produção de mensagens multimodais, promovem a capacidade do pensamento crítico (critical thinking), envolvem os participantes de maneira ativa, aumentam a autoestima e reduzem a ansiedade dos envolvidos (LAMY; HAMPEL, 2007).

Na perspectiva dos multiletramentos, a formação para o trabalho em equipe ganha uma dimensão marcante, uma vez que a produção de conhecimentos na era atual depende das capacidades interpessoal e intrapessoal dos indivíduos para o criar e o colaborar on-line em contextos socioculturais diferentes. As WebQuests como ambientes de pesquisa colaborativa podem propiciar o desenvolvimento da capacidade do professor de inglês para agir em colaboração com colegas, alunos e pessoas do mundo todo no meio on-line. Podem ainda contribuir para o seu letramento digital, multimodal e crítico, favorecendo sua participaçăo pessoal e cívica em níveis locais e globais pela internet. Como consequência de sua familiaridade com o meio virtual, pode transformar o seu fazer pedagógico ao incorporar as práticas multiletradas da era cibernética à sala de aula de inglês e também ao processo de sua formação profissional.

Uma WebQuest compõe-se de seis blocos ou componentes: (1) uma introdução concisa que fornece informaçôes relevantes, esclarecendo o que vai

\footnotetext{
${ }^{7}$ No site principal (http://webquest.org), mantido pela Universidade de San Diego, existem vários mecanismos de busca que podem ser utilizados para acesso a esses ambientes.

${ }^{8}$ Minha tradução para "a scaffolded learning structure".
} 
ser desenvolvido em colaboração entre os participantes; (2) uma tarefa factível e desafiadora para captar o interesse dos que trabalham em coautoria para alcançar objetivos comuns; (3) o processo que será vivenciado pela equipe de participantes por meio de uma descrição passo a passo do que deve ser feito; (4) os recursos necessários para o cumprimento da tarefa, como, por exemplo, as fontes de pesquisa on-line; (5) uma rubrica com os itens de avaliação; (6) uma conclusão que revê o que foi feito e que incentiva trabalhos futuros (DIAS, 2010). Opcionalmente, inclui um bloco de créditos no qual as referências utilizadas são colocadas, assim como os agradecimentos aos que contribuíram para a realização do projeto. Além desses blocos, há a parte do professor que se constitui das seguintes seções: introdução; público-alvo em potencial; objetivos curriculares a serem alcançados, processo; recursos. A página principal de uma WebQuest apresenta-se, mais ou menos, no formato a seguir (FIG.1), sendo que os seis atributos e a parte do professor podem estar dispostos verticalmente à esquerda ou horizontalmente, na parte de baixo ou de cima do site.

\section{Choosing an occupation}

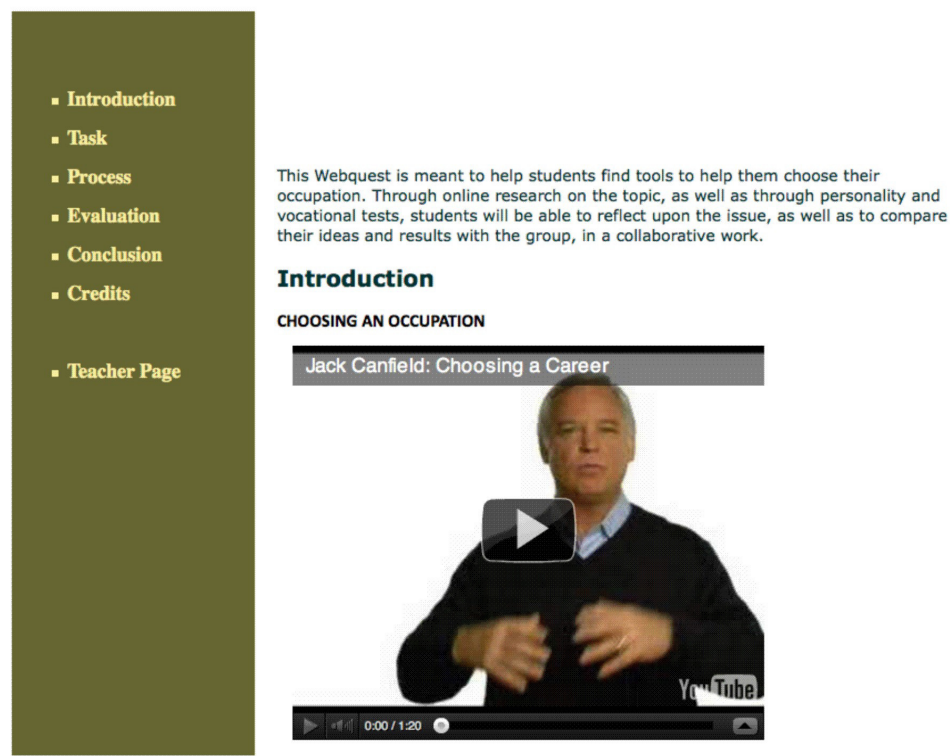

FIGURA 1 - WebQuest. Choosing an Occupation

Fonte: ARAÚJO et al., 2011, com printscreen de $<$ http://www.youtube.com/watch?v=9EjGUmMVFIA $>$.

${ }^{9}$ http://questgarden.com/110/28/0/101003144056/index.htm 
Em sua própria estrutura por meio de blocos, as WebQuests já se apresentam como ambientes digitais multimodais. $O$ indivíduo que navega por elas pode ir de um bloco a outro, ir à parte conclusiva e voltar ao início, percorrendo-as da maneira que melhor lhe convier por meio dos hiperlinks presentes em cada uma de suas seçōes, concorrendo para o seu posicionamento crítico frente ao que lê e interpreta. Além disso, quem as visita pode também acessar filmes, vídeos, podcasts, informaçôes escritas, visitar sites diversos pelos endereços que são fornecidos, principalmente no bloco denominado "Recursos". No design de suas seções, o criador desses espaços digitais pode inserir vários modos semióticos para produzir a mensagem, atribuindo um valor estético mais atraente ao público-alvo que tem em mente e aos contextos socioculturais a que se dirige. Uma WebQuest criada para crianças, por exemplo, vai lidar com o conteúdo e com os aspectos de multimodalidade de uma maneira bem diferente daquela que é dirigida a adolescentes ou adultos. $\mathrm{O}$ autor/produtor orienta-se pela função social do ambiente de aprendizagem colaborativa que está criando e faz pleno uso de sua criatividade para expressar significados.

A grande maioria das WebQuests criadas enfatizam a leitura e a escrita como capacidades essenciais à pesquisa on-line, embora muitas delas façam uso de links a vídeos e a podcasts. Usualmente, contêm imagens, fotografias e gráficos em sua teia multimodal e o layout é organizado pelo uso dos cinco pilares da editoraçăo eletrônica: ${ }^{10}$ (1) a organização da página impressa; (2) os efeitos tipológicos; (3) os recursos gráficos; (4) os efeitos visuais; (5) os organizadores de texto relativos aos títulos, aos subtítulos, às legendas, aos cabeçalhos e aos rodapés, aos créditos de continuação e à numeração de páginas (DIAS; BAMBIRRA; ARRUDA, 2012).

Ler e escrever faz parte de qualquer processo de pesquisa; o leitor transforma-se em autor e o autor em seu próprio leitor, do princípio ao fim da investigação. No caso da coautoria na construção e produção de significados, como acontece nas WebQuests, participantes diferentes se alternam nesses papéis e orquestram diferentes modos semióticos para construir significados, agregando ainda uma visão crítica multifacetada pelo trabalho feito em grupo. Como o espaço virtual facilita a produção dos textos multimodais do século XXI, a criação conjunta de WebQuests envolve também

\footnotetext{
${ }^{10}$ Do inglês, desktop publishing, refere-se ao processo de diagramar textos em computadores pessoais. Alternativa para professores e educadores que podem criar os layouts de seus materiais de ensino.
} 
decisões consensuais relativas ao design e layout de seus ambientes de aprendizagem para a inserção de diferentes códigos semióticos (WILLIAMS, 2005). Capacitar o professor de inglês para compreender e produzir textos multimodais faz também parte de sua formação para os multiletramentos da era contemporânea.

\section{Aprendizagem colaborativa}

Estreitamente ligada à teoria sócio-histórico-cultural de Vygotsky (1987), esse tipo de proposta relacionada ao aprender em colaboração apoia-se no trabalho em conjunto de um grupo de aprendizes que, em parceria, resolvem um problema, completam uma tarefa ou criam um produto. Fundamenta-se no pressuposto básico de que aprender é um ato social que envolve interaçōes entre os participantes e, por meio delas, ocorre a aprendizagem, um pressuposto em consonância com o conceito de zona de desenvolvimento proximal (VYGOTSKY, 1987). Tal conceito é visto como a distância entre o nível de desenvolvimento real, evidenciado pela solução independente de problemas (pelo próprio aprendiz), e o nível de desenvolvimento potencial, determinado pela solução de problemas por meio da colaboração entre o aprendiz e um par mais competente, por meio de estratégias de scaffolding ('andaime') (WOOD; BRUNER; ROSS, 1976). Significa, pois, em linhas gerais, a assistência fornecida aos aprendizes que trabalham em colaboração por meio de interações/mediações que ocorrem pelas discussões face a face ou pelo uso de artefatos tecnológicos. No processo de busca da solução de um objetivo comum, os participantes assumem responsabilidade pela própria aprendizagem e também pela dos colegas, parceiros em colaboração. Dinâmicas colaborativas envolvem, pois, uma interdependência positiva, o que evidencia a noção do êxito individual vinculado ao do grupo (BARBOSA; PESSÔA, 2005), remetendo à ideia central de colaboração proposta por Palloffe Pratt (2005, p. 4), "when I succeed, we succeed".

Os recursos disponíveis pelas WebQuests viabilizam o desenvolvimento das duas noções básicas da aprendizagem colaborativa, o compartilhamento e o empréstimo de conhecimento entre os envolvidos (DIAS, 2008 apud HYLAND, 2004). A noção de compartilhamento (shared knowledge) referese à ideia de que alunos aprendendo juntos aprendem mais do que indivíduos trabalhando separadamente. A outra, a de empréstimo (borrowed knowledge), está relacionada à ideia de que alunos aprendendo com um par mais competente entendem melhor as tarefas de aprendizagem e, em consequência, aprendem de maneira mais eficiente. Essas noçôes apoiam-se na perspectiva 
vygotskiana que preconiza que a interação social é de importância vital no desenvolvimento cognitivo por ser considerada mediadora desse processo. Aprender, na verdade, é um processo de interação em práticas sociais e culturais situadas em contextos de comunicação entre indivíduos.

Pesquisas recentes, com foco na colaboração e no uso de tecnologias digitais na produção escrita em inglês, revelam que tal combinação de açóes resulta em textos mais bem escritos em termos de seus aspectos discursivos e linguísticos para atender aos seus propósitos comunicativos e às suas condições de produção (SANTOS, 2011; VEADO, 2008).

\section{A investigação}

Contexto. A investigação realizada apoiou-se na perspectiva da necessária integração dos multiletramentos à formação do professor de inglês (FREIRE, 2009) e ao seu fazer pedagógico (ANSTEY; BULL, 2010), nos princípios da aprendizagem colaborativa (LAMY; HAMPEL, 2007; SANTOS, 2011; VEADO, 2008) e na visão de que todo texto é multimodal (KRESS, 2003). Subjacente está a ideia de que as tecnologias digitais favorecem a composição de textos que integram vários modos semióticos na produção dos significados, como, por exemplo, o som, o espaço, a imagem, o movimento, além do linguístico, predominante em décadas anteriores. Reconhece-se, hoje, que esses recursos são usados em combinação para realçar diferentes efeitos a textos de gêneros diversificados.

Os participantes desta investigação foram incentivados a aprender sobre WebQuests no processo de conhecer na ação, refletir na e sobre a ação (SCHÖN, 1983) durante o envolvimento com dois ambientes de aprendizagem sobre essa ferramenta de pesquisa on-line, visando aos multiletramentos necessários ao professor de inglês da era atual. Aconteceram discussóes também sobre o impacto das tecnologias no design das WebQuests por permitirem não só o uso de diferentes modos semióticos, mas também a organização do layout da página por meio de cores, aproveitamento do espaço, diferentes tipos de fontes e estilos, além da ampliação das possibilidades de interação com outras fontes de informação pelos hiperlinks fornecidos.

No processo reflexivo de desenvolvimento de conhecimento sobre WebQuests, os participantes, primeiro, entenderam o que são esses ambientes de aprendizagem e refletiram sobre o seu potencial para a própria formação e a de seus alunos para situações reais de pesquisa on-line. Foram incentivados a visitar várias WebQuests e a explorar as características multimodais desse 
ambiente. Interagiram entre eles para a criação colaborativa das próprias WebQuests para atender aos seus objetivos de ensino de inglês. Os princípios da abordagem colaborativa foram discutidos para que os participantes percebessem a importância da colaboração para a autoria conjunta que envolve o aproveitamento de diferentes pontos de vista e de capacidades cognitivas diversas (SANTOS, 2011).

A investigação empírica, associada à pergunta de pesquisa, "As WebQuests favorecem o desenvolvimento do letramento digital do professor de inglês de modo a se formar para os desafios educacionais da era virtual?", foi desenvolvida por meio de um estudo de caso, no período de março a maio de 2011. O objetivo principal desse método de pesquisa é "descrever o caso em seu próprio contexto", e sua essência consiste em analisá-lo cuidadosamente e de maneira holística (JOHNSON, 1991 apudVEADO, 2008) e torna-se difícil prever os resultados finais da investigação. A entidade sob análise pode ser, por exemplo, um aluno ou grupo de alunos, um professor ou um programa.

Os participantes eram professores em educação continuada, que estavam matriculados em um curso de especialização em ensino de inglês (CEI) da Faculdade de Letras da UFMG - 23 iniciaram o curso, mas cinco desistiram, sendo, então, dezoito professores ao final do curso. Cabe salientar que eles se mostravam motivados, especialmente para o desenvolvimento de seus multiletramentos, para que pudessem vir a fazer usos de recursos da web e da noção sobre multimodalidade com seus alunos de uma maneira crítica e responsável. Deixavam isso claro pela disposição em envolver intensivamente nas atividades do curso e pelo desejo de aprender mais para mudar e/ou transformar sua prática pedagógica.

\section{Coleta de dados}

Dois questionários, denominados Questionário 1 e Questionário 2, foram aplicados para identificar o perfil digital dos participantes, um no início da investigação e o outro ao final. Havia uma pergunta específica que visava investigar o conhecimento anterior dos participantes sobre WebQuests e o adquirido ao longo do estudo investigativo. ${ }^{11}$

\footnotetext{
${ }^{11}$ Ambos os questionários foram criados no Google Docs e podem ser acessados nestes endereços, respectivamente: <https://spreadsheets.google.com/viewform?formkey= dDRpcFRoREd2bFkxbHdxemhLdVU1TWc6MQ> e <https://spreadsheets. google.com/viewform?formkey=dHdNdkFzcnJ4MG92cjVPZEdnNGpsNHc6MQ>.
} 
Durante o estudo de caso, os participantes interagiram com dois ambientes de aprendizagem, a saber, $A$ WebQuest about WebQuests e Creating Your Own WebQuest. No primeiro, construíram conhecimento sobre esta ferramenta e forneceram breves relatos escritos sobre as suas percepções em duas de suas atividades, "Short reports" e "Position papers". Os participantes criaram as suas próprias WebQuests colaborativamente no processo de interagir com o segundo ambiente, Creating Your Own WebQuest. Os grupos decidiram sobre o tema a ser trabalhado.

Cada uma das quatro WebQuests produzidas por eles foram avaliadas pela rubrica, Criteria for Assessing Best WebQuests (MARCH, 2011). ${ }^{12}$ Essa rubrica inclui oito itens para o processo de avaliação de uma WebQuest: introdução, tarefa, conhecimento comum a todos pelos sites indicados, papéis dos envolvidos, uso extensivo da web, pensamento crítico, feedback e conclusão. No item "introdução" foram acrescentados, para fins deste estudo, estes aspectos à avaliaçăo: o layout da página (cores, fontes diferentes etc.). Para cada um desses oito itens, a rubrica especifica três medidas de qualidade: baixa (low); média (medium) e alta (high), tendo em vista descritores específicos para cada um deles. Os pontos a serem atribuídos são 1,2 e 3 , respectivamente.

Por exemplo, tendo em vista o item "introdução", o avaliador deve atribuir 1 ponto a uma WebQuest que não apresenta apelos significativos ao engajamento do aprendiz para realizá-la; 2 pontos àquela que mostra algum esforço para persuadir o aprendiz a se envolver com uma tarefa que lhe parece desafiadora; e 3 pontos à WebQuest que incita ou desafia o aprendiz a se envolver com um ambiente de aprendizagem que lhe parece relevante para aprender mais sobre um determinado tópico.

A tabela para a avaliação final, conforme a rubrica de March (2011), ${ }^{13}$ especifica que são três estrelas para as WebQuests que receberem entre 13 e 15 pontos, 4 para aquelas que ficarem com totais entre 16 e 19 e 5 estrelas para as quais forem atribuídos pontos entre 20 e 24 .

\section{Análise dos dados}

Os questionários. A análise dos resultados dos dois questionários revela que, da posição de quase total desconhecimento sobre o significado de WebQuests e de seus atributos (87\%), os participantes mostraram não só ter

\footnotetext{
${ }^{12} \mathrm{http}: / /$ bestwebquests.com/bwq/matrix.asp

${ }^{13} \mathrm{http}: / /$ bestwebquests.com/bwq/matrix.asp
} 
aprendido sobre elas (100\%), mas também revelaram sua intenção em passar a usá-las com seus alunos (89\%). ${ }^{14}$

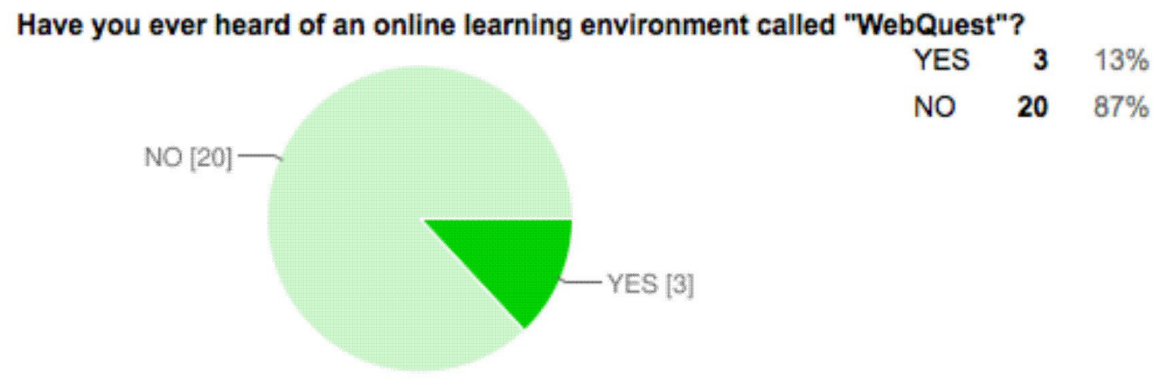

FIGURA 2-Questionário 1

Fonte: $<$ https://spreadsheets.google.com/viewform?formkey= dDRpcFRoREd2bFkxbHdxemhLdVU1TWc6MQ>.

32768327683276832768

4. Do you know what WEBQUESTS mean now?

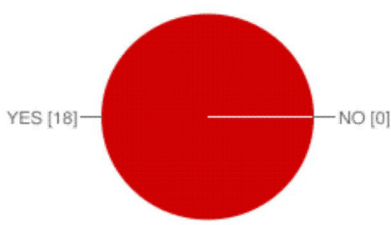

YES

No

18

0

$100 \%$

$0 \%$

(1)

5. Are you going to use WebQuests with your students?

$\begin{array}{lrr}\text { YES } & \mathbf{1 6} & 89 \% \\ \text { NO } & \mathbf{2} & 11 \%\end{array}$

FIGURA 3-Questionário 2

Fonte: <https://spreadsheets.google.com/

viewform?formkey=dHdNdkFzcnJ4MG92cjVPZEdnNGpsNHc6MQ>.

${ }^{14}$ Vale lembrar que, no início do curso, eram 23 participantes e, ao final, dezoito. 
Os ambientes de aprendizagem. A criação de WebQuests pelos participantes, em colaboração em cada um dos grupos formados, revela que eles não só aprenderam sobre o ambiente como também foram capazes de criá-los, incorporando as características multimodais do gênero aos seus trabalhos. Os títulos de suas WebQuests são estes: The History of the English Language; Globalization and the English Language; Have you Ever Considered Studying Abroad?; Behind The Cinema. ${ }^{15}$ Minha avaliação dos quatro ambientes produzidos pelos alunos, tendo em vista a rubrica criada por March (2011), pode ser vista a seguir.

\section{QUADRO 1}

Rubrica de avaliação

\begin{tabular}{|c|c|c|c|}
\hline Critérios & Baixa $-1 p t$ & Média - 2pts & Alta-3pts \\
\hline $\begin{array}{l}\text { Introdução, layout } \\
\& \text { multimodalidade }\end{array}$ & & $\begin{array}{c}\text { History of the English Language } \\
\text { Globalization } \\
\text { Behind the Cinema }\end{array}$ & Studying Abroad \\
\hline Tarefa & & $\begin{array}{c}\text { Globalization } \\
\text { Studying Abroad } \\
\text { Behind the Cinema }\end{array}$ & History of the English Language \\
\hline $\begin{array}{l}\text { Conhecimento } \\
\text { comum a todos }\end{array}$ & & & $\begin{array}{c}\text { History of the English Language } \\
\text { Globalization } \\
\text { Studying Abroad } \\
\text { Behind the Cinema }\end{array}$ \\
\hline Papéis & & $\begin{array}{c}\text { Globalization } \\
\text { Studying Abroad }\end{array}$ & History of the English Language \\
\hline Uso da web & & & $\begin{array}{c}\text { History of the English Language } \\
\text { Globalization } \\
\text { Behind the Cinema } \\
\text { Studying Abroad }\end{array}$ \\
\hline Pensamento crítico & & $\begin{array}{c}\text { Globalization } \\
\text { Behind the Cinema }\end{array}$ & $\begin{array}{c}\text { History of the English Language } \\
\text { Studying Abroad }\end{array}$ \\
\hline Feedback & & $\begin{array}{c}\text { History of the English Language } \\
\text { Globalization } \\
\text { Behind the Cinema }\end{array}$ & Studying Abroad \\
\hline Conclusão & & $\begin{array}{c}\text { History of the English Language } \\
\text { Globalization } \\
\text { Studying Abroad } \\
\text { Behind the Cinema }\end{array}$ & \\
\hline
\end{tabular}

${ }^{15}$ Disponíveis respectivamente em <http:/questgarden.com/123/99/4/110413094633/ index.htm>; <http://questgarden.com/123/84/6/110410174505>; <http://questgarden. com/123/24/3/110403181206>; <http://questgarden.com/124/11/5/110412163038>. 


\begin{tabular}{|l|c|c|}
\hline WebQuests & Pontos & Número de estrelas \\
\hline History of the English Language & 21 pontos & 5 estrelas \\
Globalization & 18 pontos & 4 estrelas \\
Studying Abroad & 18 pontos & 4 estrelas \\
Behind the Cinema & 16 pontos & 4 estrelas \\
\hline
\end{tabular}

Fonte: Elaboração própria.

Parece possível afirmar que os professores desenvolveram habilidades relacionadas aos multiletramentos, especialmente ao digital, ao multimodal e ao crítico. Isso provavelmente os torna hábeis a lidar com as práticas multiletradas atuais em seu processo de formação, capazes de interagir com as novas práticas sociais advindas do uso de tecnologias.

Os ambientes de aprendizagem criados pelos participantes evidenciaram a importância da abordagem colaborativa de autoria de textos. Os dados coletados nos fóruns de interações, criados no espaço "Voy" (www.voy.com) demonstram que os grupos trabalharam colaborativamente em busca de um objetivo comum - a criação de WebQuests para serem utilizadas pelos seus alunos. Os fóruns de cada um dos grupos revelam que aconteceram discussões frutíferas para esse fim.

Breves relatos. As percepções dos alunos, professores de inglês, foram coletadas por meio de relatos fornecidos em "Short reports" e "Position papers" do ambiente $A$ WebQuest about WebQuests. A análise dos dados revela que os participantes desenvolveram uma atitude muito positiva em relação a esse ambiente de aprendizagem e de formação do professor de inglês, evidenciada em seus "Short reports" e em alguns de seus "Position papers". Essa atitude positiva pode ser verificada pelo que escreveram, como mostram alguns excertos de seus relatos a seguir.

After reading and surfing through some of the WebQuests I came to the conclusion that they are a priceless tool to be used in class, which I hadn't come across yet. (Participante 1).

There, students will find the necessary tools, such as related sites, videos or interviews that will enable them to accomplish the task proposed. The WebQuest gives both teachers and students greater autonomy to do their work. (Participante 2).

The Use of WebQuests in my Teaching Practice 
I have to say I found WebQuests extremely useful. Barney Dodge's idea of creating an online environment where teachers can develop quests as a task for students is outstanding. This digital era where we live today requires the use of internet not only as a resource of information but also for many different kinds of social use. WebQuests are an efficient way for teachers to develop tasks related to their particular subject as well as any kind of extra information they feel like having their students have access to. It is an efficient way to call out students' attention since we are dealing with digital native students. As Prensky would state, "our students today are all native speakers of the digital language of computers, video games and the internet". (Participante 3).

Today's teachers have to learn to communicate in the language and style of their students. This doesn't mean changing the meaning of what is important, or of good thinking skills. But it does mean going faster, less step-by step, more in parallel, with more random access, among other things. As educators, we need to be thinking about how to teach both Legacy and Future content in the language of the Digital Natives. The first involves a major translation and change of methodology; the second involves all that PLUS new content and thinking. It's not actually clear to me that is harder - "learning new stuff" or "learning new ways to do old stuff." I suspect it's the latter. (Participante 4).

Com base nos relatos, então, parece possível afirmar que os professores apropriaram-se de práticas multiletradas e que provavelmente vão fazer uso das WebQuests com seus alunos em sua prática pedagógica. Além disso, mostraramse otimistas pelo que aprenderam e pelo que podem fazer para melhorar suas aulas em relação aos seus alunos, como evidenciam os excertos dos depoimentos a seguir, coletados ao final do curso.

It was very good to learn about something that I've never heard before. Thanks. (Participante 5).

I liked the way you supported us in our lessons and the way you guided us to the right path. Thanks for being so patient and for helping us to be better teachers. Best wishes! (Participante 6).

I apreciate the work she did with us. I really learned many important things that will help in my teaching activity. I would like to thank her for the time we spent together and thank for many important materials she gave us. Thank you [...] (Participante 7). 
I really appreciated this online course. It was exactly what I was looking for in my postgraduate course. Discussions, suggestions and activities that fit my everyday practice. Thanks for giving us this opportunity. (Participante 8).

Your subject was practical, objective and pleasurable. It changed my concepts about online disciplines. (Participante 9).

I want just say "thank you". I liked your discipline so much. I could improve my English and my experiences with digital resoucers. And now, I intend to put it in practice. (Participante 10).

\section{Considerações finais}

$\mathrm{O}$ ambiente WebQuest configura-se como adequado à formação do professor de inglês, uma vez que oferece múltiplas oportunidades de colaboração e de vivência on-line para o desenvolvimento das práticas sociais multiletradas da era cibernética. No processo de conhecer esses ambientes, o professor constrói conhecimento sobre o meio virtual e suas ferramentas para, então, criar suas próprias WebQuests, que podem se tornar recursos significativos para os alunos, participantes ativos da cultura cibernética. Entre o conhecer e o criar, como experimentado pelos participantes da investigação desenvolvida, o professor tem a oportunidade de refletir, problematizar, investigar, levantar questões, desenvolver práticas multiletradas e colaborar para, assim, vivenciar o desafio de construir um ambiente multimodal de aprendizagem em consonância com os compromissos de uma educação transformadora. É possível afirmar que os multiletramentos, especialmente o digital, o multimodal e o crítico, construídos por meio do envolvimento com WebQuests, criam condições que favorecem a inclusão crítico-social e o desenvolvimento da fluência tecnológica do professor de inglês que permitem a ele conectar-se a uma educação libertadora, consoante com as demandas sociais do mundo do trabalho e da necessidade de se formar (e formar outros) para uma cidadania plena (ALMEIDA, 2005). Parece possível também afirmar que o conhecimento-na-ação, reflexão-na-ação e reflexão-sobre-a-ação (SCHÖN, 1983), construídos pelos participantes da investigação pelo uso de WebQuests, criaram oportunidades para o repensar a prática pedagógica dos envolvidos e é provável que esse realinhamento vá permitir a transformação de suas ações rotineiras, já cristalizadas, em outras alternativas de ensino e aprendizagem para a sua formação e para o seu contexto de atuação, embora 
isso possa não vir a se concretizar. Para aprender e conhecer, o professor precisa "[p] esquis[ar] para constatar, constatando, [intervém], intervindo, [educa] e [se educa]" (FREIRE, 1996, p. 29). Tal ciclo de formação o faz crescer e buscar o melhor para si e seus alunos. Sem dúvida, o cenário sócio-histórico atual, em contínua transformação, requer novas perspectivas educacionais para o ensino de inglês e novos papéis para professores e alunos, tendo em vista os desafios da era cibernética.

\section{Referências}

ALMEIDA, M. E. B. Letramento digital e hipertexto: contribuiçõos à educação. In: PELLANDA, N. M. C.; SCHLÜNZEN, E. T. M.; SCHLÜZEN JUNIOR, K. (Org.). Inclusão digital: tecendo redes afetivas/cognitivas. Rio de Janeiro: DP\&A, 2005.

ANSTEY, M.; BULL, G. Evolving Pedagogies, Reading and Writing in a Multimodal World. Australia: Education Services Australia, 2006.

ARAÚJO, K.; AZEREDO, C.; FERREIRA, S.; FREITAS, P.; MELO, A. Choosing an Occupation. Disponível em: <http://questgarden.com/110/28/0/ 101003144056/index.htm>. Acesso em: 18 fev. 2012.

BARBOSA, A. C. L. S.; PESSÔA, A. C. Dinâmicas colaborativas no ensino online: Estado da arte. 2007. Disponível em: <http://www.abed.org.br/ congresso2007/tc/7302007113323AM.pdf>. Acesso em: 13 mar. 2012.

BULL, G.; ANSTEY, M. Evolving Pedagogies, Reading and Writing in a Multimodal World. Melbourne: Education Services Australia, 2010.

CANFIELD, J. Choosing an Occupation. Disponível em: <http://www.youtube. com/watch?v=9EjGUmMVFIA $>$ Acesso em: 13 mar. 2012.

COPE, B.; KALANTZIS, M. (Ed.). Multiliteracies: Literacy Learning and the Design of Social Futures. London: Routledge, 2000.

DIAS, R. Gêneros digitais e multimodalidade: oportunidades on-line para a escrita e a produção oral em inglês no contexto da educação básica. In: Gêneros textuais: teoria e prática de ensino em LE. Campinas: Mercado de Letras, 2011. No prelo.

DIAS, R.; BAMBIRRA, R.; ARRUDA, C. Aprender a aprender: metodologias para estudos autônomos. Belo Horizonte: Editora UFMG, 2012. No prelo.

DIAS, R. WebQuests no processo de aprendizagem de L2 no meio on-line. In: MENEZES, V. L. (Org.). Interação e aprendizagem em ambiente virtual. Belo Horizonte: Editora UFMG, 2010. p. 359-394. 
DODGE, B. A WebQuest about WebQuests. 2008. Disponível em: <http:// webquest.sdsu.edu/webquestwebquest.html>. Acesso em: 12 fev. 2012.

DODGE, B.; MARCH, T. Página principal de WebQuests. 2007. Disponível em: <http://webquest.org/index.php>. Acesso em: 12 fev. 2012.

FREIRE, M. M. Formação tecnológica de professores: problematizando, refletindo, buscando. In: SOTO, U.; MAYRINK, M. F.; GREGOLIN, I. V. (Org.). Linguagem, educação e virtualidade: experiências e reflexões. São Paulo: Cultura Acadêmica, 2009. v. 1, p. 13-28.

FREIRE, P. Pedagogia da autonomia: saberes necessários à prática educativa. São Paulo: Paz e Terra, 1996.

FREIRE, P. Pedagogia do oprimido. 17. ed. Rio de Janeiro: Paz e Terra, 1987.

GUIMARÂES, A. M.; DIAS, R. Ambientes de aprendizagem: reengenharia da sala de aula. In: COSCARELLI, C. V. (Org.). Novas tecnologias, novos textos, novas formas de pensar. Belo Horizonte: Autêntica, 2002. p. 23-42.

HYLAND, K. Genre and Second Language Writing. Michigan: The University of Michigan Press, 2004.

HYLAND, K. Genre Pedagogy: Language, Literacy and L2 Writing Instruction. Journal of Second Language Writing, n. 16, p. 148-164, 2007. Disponível em: <http://www2.caes.hku.hk/kenhyland/files/2012/08/Genre-pedagogy_ language-literacy-and-L2-writing-instruction1.pdf >. Acesso em: 20 set. 2012. KALANTZIS, M.; COPE, B. New Learning: Elements of a Science Education. Cambridge (UK): Cambridge University Press, 2008.

KRESS, G. Literacy in the New Media Age. London; New York: Routledge, 2003. LAMY, M. N.; HAMPEL, R. Online Communication in Language Learning and Teaching. Basingstoke: Palgrave Macmillan, 2007.

MARCH, T. Criteria for Assessing Best WebQuests. 2011. Disponível em: <http:/ /bestwebquests.com/bwq/matrix.asp>. Acesso em: 12 fev. 2012.

MARCH, T. The Learning Power of WebQuests. Educational Leadership, v. 61, n. 4. p. 42-47, Dec. 2003-Jan. 2004. Disponível em: <http://tommarch.com/ writings/ascdwebquests>. Acesso em: 20 set. 2012.

PALLOFF, R. M.; PRATT, K. Collaborating Online: Learning Together in Community. San Francisco: Jossey-Bass, 2005.

SANTOS, V. A. R. de A. Wikis na produção textual colaborativa de notícias online em inglês como L2 no meio virtual: um estudo de caso. 2011. $223 \mathrm{f}$. Dissertação (Mestrado em Estudos Linguísticos), Faculdade de Letras, Universidade Federal de Minas Gerais, Belo Horizonte, 2011. 
SCHÖN, D. A. The Reflective Practitioner: How Professionals Think in Action. Nova York: Basic Books, 1983.

SOARES, M. Letramento: um tema em três gêneros. 2. ed. Belo Horizonte: Autêntica, 2003.

TASMANIA: Explore the Possibilities - Department of Education - Australian Curriculum. Critical Literacy. Spring 1996. Disponível em: <http://www.education. tas.gov.au/curriculum/standards/english/english/teachers/critlit>. Acesso em: 26 fev. 2012.

VEADO, M. C. M. Colaboração no processo de produção textual em uma atividade online: Um estudo de caso com o gênero resenha de filme. 2008. 194 f. Dissertação (Mestrado em Estudos Linguísticos), Faculdade de Letras, Universidade Federal de Minas Gerais, Belo Horizonte, 2008.

VYGOTSKY, L. S. A formação social da mente. 6. ed. São Paulo: Martins Fontes, 1996.

WALLACE, C. Critical Reading in Language Education. New York: PalgraveMacmillan, 2005.

WALSH, M. Multimodal Literacy: What Does It Mean for Classroom Practice? Australian Journal of Language and Literacy, v. 33, n. 3, p. 211-239, 2010. Disponível em: <http://www.alea.edu.au/documents/item/63>. Acesso em: 12 fev. 2012.

WOOD, D. J.; BRUNER, J. S.; ROSS, G. The Role of Tutoring in Problem Solving. Journal of Child Psychiatry and Psychology, v. 17, n. 2, p. 89-100, Dec. 2006. Disponível em: <http://onlinelibrary.wiley.com/doi/10.1111/j.14697610.1976.tb00381.x/pdf>. Acesso em: 12 fev. 2012.

Recebido em 15/03/2012. Aprovado em 14/08/2012. 